\title{
Morphology and distribution of antennal sensilla in a mealybug parasitoid, Anagyrus sp. near pseudococci (Hymenoptera, Encyrtidae)
}

\author{
Fortuna, T.M.*, Franco, J.C.** and Rebelo, M.T.*** \\ * Department of Terrestrial Ecology, Netherlands Institute of Ecology (NIOO-KNAW), 6700 AB Wageningen, \\ The Netherlands \\ ** Centro de Estudos Florestais, Instituto Superior de Agronomia, Universidade Técnica de Lisboa, 1349-017 \\ Lisboa, Portugal \\ *** Departamento de Biologia Animal (DBA)/Centro de Estudos do Ambiente e do Mar (CESAM), Faculdade de \\ Ciências da Universidade de Lisboa, Campo Grande, 1749-016 Lisboa, Portugal
}

E-mail: mtrebelo@fc.ul.pt

The antennae of adult insects have various types of sensilla with different functions in the various behaviors of adult life. Parasitoid females are known to rely on these important sensory receptors in their antennae to locate and select the host [1-3]. Anagyrus sp. near pseudococci (4) is a solitary endoparasitoid of pest mealybugs (Hemiptera, Pseudococcidae), such as Planococcus ficus (Signoret) and P. citri (Risso) [5]. The females of $A$. sp. near pseudococci were recently shown to respond to the sex pheromone of $P$. ficus and use this kairomonal cue in host location [5,6]. However, little is still known about the antennal receptors that might be involved in the parasitoid host selection behavior.

In this study, using SEM (JEOL JSM 5200 LV), we describe the morphology and distribution of sensilla on the antenna of 18 females and 2 males of $A$. sp. near pseudococci.

Eight types of antennal sensilla were found on adult wasps. Trichodea, placodea, basiconica, and chaetica (type 1, type 3 and type 4) sensilla were observed in both sexes, while chaetica type 2 sensilla were present only in female wasps, and tridentate scale-shaped type sensilla were present only in males.

Detailed examination of sensilla morphological features, such as pore presence and numbers suggests that the multiporous sensilla, including chaetica type 3 and 4, basiconica and placodea may play a role in olfaction, whereas the uniporous chaetica sensilla of type 1 and 2 may act as contact chemoreceptors. The abundant and widely distributed trichodea sensilla are presumably mechanoreceptors. The females of $A$. $s p$. near pseudococci showed higher density of chemoreceptor sensilla than males, and these receptors were mainly distributed in the ventral side of the antenna club (tip). These differences may be related to infochemical detection (e.g. antennation) during the host selection behavior of female wasps, particularly the presence and distribution of chaetica sensilla of type 2, which are only present on females, and type 4.

[1] Bleeker, M.A.K. et al., Microsc Res Techniq, 63, 266-273, 2004.

[2] van Baaren, J. et al., In: Modern Research and Educational Topics in Microscopy, Méndez-Vilas, A. and

Diaz, J., eds 345-352, 2007.

[3] Roux, O. et al., Microsc Res Techniq, 68, 36-44, 2005.

[4] Triapitsyn, S.V. et al., Biol Control, 41, 14-24, 2007.

[5] Franco, J.C. et al., Biol Control, 58, 230-238, 2011.

[6] Franco, J.C. et al., Entomol Exp Appl, 126, 122-130, 2008. 
Funding source: Portuguese Science Foundation (FCT) to project PTDC/AGR-AAM/099560/2008
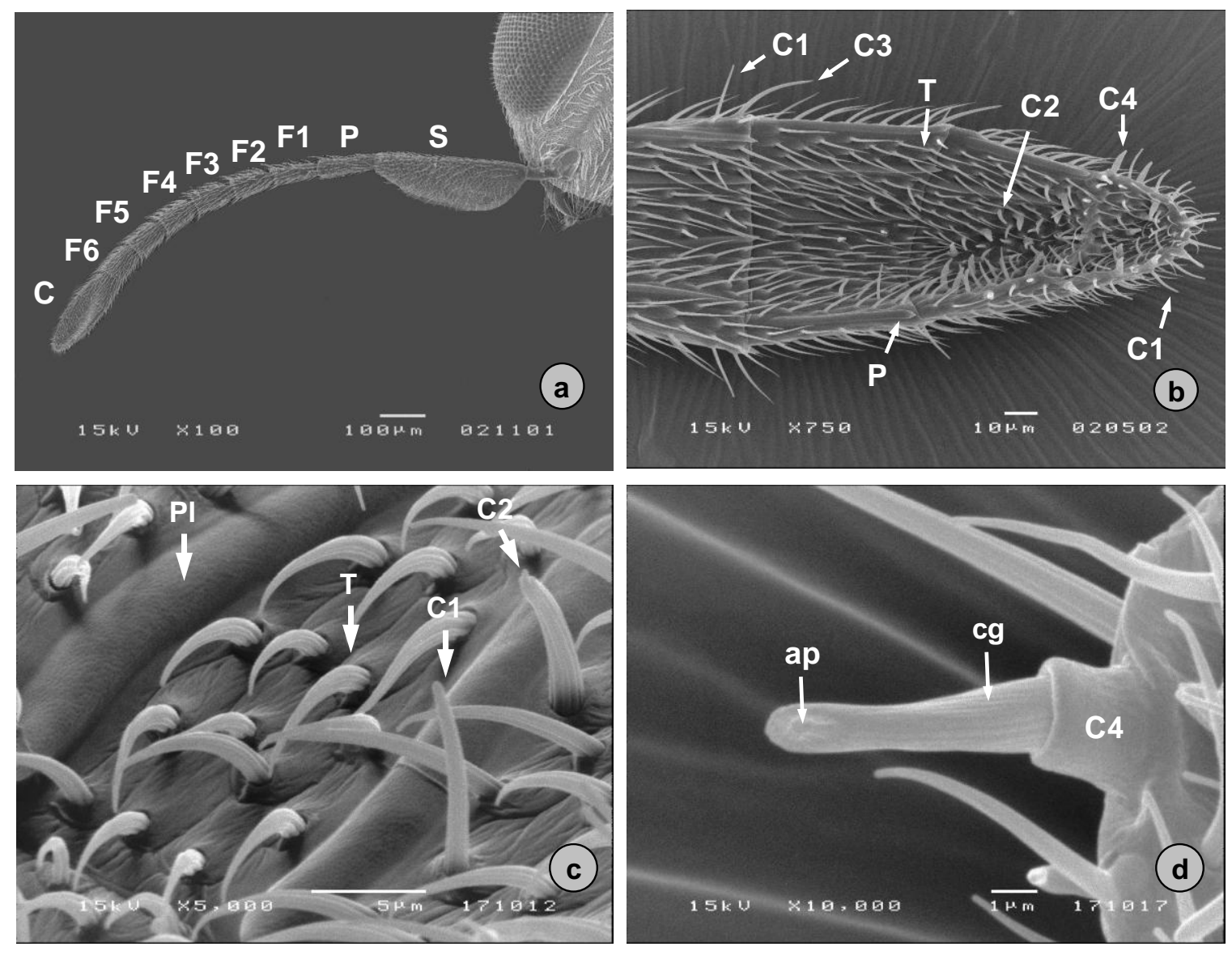

Figure 1. Antenna of Anagyrus sp. near pseudococci females.

a) Different antennal segments. S, scape; P, pedicel; F1-F6, funicle 1 to 6; C, club. SEM $\times 100$. Scale bar = $100 \mu \mathrm{m}$. b) Ventral side of the antennal club showing some types of sensilla. T, trichodea sensilla; Pl, placodea sensilla; C1, chaetica sensilla type 1; C2, chaetica sensilla type 2 ; C3, chaetica sensilla type 3; C4, chaetica sensilla type 4 . SEM $\times 750$. Scale bar $=10 \mu \mathrm{m}$. c) Detail of sensilla in the ventral side of the club. P, placodea sensillum showing multiple pores; T, trichodea sensillum with helicoidal cuticular groves; $\mathrm{C} 1$, chaetica sensillum type 1; C2, chaetica sensillum type 2 showing longitudinal cuticular groves and a sensillium projection with potential pore. $\mathrm{SEM} \times 5000$. Scale bar $=5 \mu \mathrm{m}$. d) Detail of a chaetica sensillum type 4 with apical pore (ap) and cuticular groves $(\mathrm{cg})$. SEM $\times 10000$. Scale bar $=1 \mu \mathrm{m}$. 